Efficacy (in per cent) of screening test in neonates and infants

\begin{tabular}{|c|c|c|c|c|}
\hline Positive test area & Sensitivity & Specificity & $\begin{array}{l}\text { Positive } \\
\text { predictive } \\
\text { value }\end{array}$ & $\begin{array}{l}\text { Negative } \\
\text { predictive } \\
\text { value }\end{array}$ \\
\hline \multirow{2}{*}{$\begin{array}{l}\text { Leucocyte esterase } \\
\text { Nitrite } \\
\text { Protein } \\
\text { Leucocyte esterase and nitrite } \\
\text { Leucocyte esterase and protein } \\
\text { Leucocyte esterase and nitrite } \\
\text { and protein }\end{array}$} & $\begin{array}{r}89 \cdot 2 \\
16 \cdot 2 \\
8 \cdot 1 \\
89 \cdot 2 \\
89 \cdot 2\end{array}$ & $\begin{array}{l}78 \cdot 2 \\
97 \cdot 6 \\
95 \cdot 1 \\
97 \cdot 6 \\
95 \cdot 1\end{array}$ & $\begin{array}{l}42 \cdot 3 \\
54 \cdot 5 \\
23 \cdot 1 \\
87 \cdot 2 \\
76 \cdot 7\end{array}$ & $\begin{array}{l}97 \cdot 6 \\
86 \cdot 6 \\
85 \cdot 2 \\
98 \cdot 5 \\
98 \cdot 0\end{array}$ \\
\hline & $89 \cdot 2$ & $71 \cdot 8$ & $36 \cdot 3$ & $99 \cdot 4$ \\
\hline
\end{tabular}

was highest (table), but the NPV of leucocyte esterase alone did not differ significantly. The nitrite test alone showed a low sensitivity and the highest specificity. The result of this test when combined with leucocyte esterase and protein did not provide additional information in infants with urinary tract infection, contrary to the results obtained from adult patients. $^{1}$

\section{Conclusion}

We have confirmed the value of urine strips as a screening test to exclude diagnosis of urinary tract infection among inpatient infants. We recommend that the test is done at the bedside using photometry to avoid the variations due to readings by nurses. The most important aspect of the test is the NPV, detection of leucocyte esterase alone or in combination with proteinuria or detection of nitrite having the most value.

The absence of leucocyturia, proteinuria, or a positive nitrite test practically excludes the diagnosis of urinary tract infection among infants and in our hospital urine cultures on infants could be reduced by $60 \%$ on the basis of this screening test.

1 Boreland PC, Stoker M. Dipstick analysis for screening of pediatric urine. J Clin Pathol 1986;39:1360-2.

2 Klein JO, Marcy SM. Infections of the urinary tract. In: Infectious diseases of the fetus and newborn infant. Philadelphia: WB Saunders Company, 1976:841-53.

\title{
Oncocytic metaplasia of the nasopharynx or extra-parotid Warthin's tumour?
}

\author{
A P Griffiths, P Dekker
}

\begin{abstract}
A case of oncocytic metaplasia obstructing the Eustachian tube in an elderly patient is described. Histologically, it was similar to Warthin's tumour of the parotid gland. The lymphocytes were predominantly $T$ cell, unlike those of Warthin's tumour which are predominantly $B$ cell. It is proposed that oncocytic metaplasia represents an early stage in the evolution of Warthin's tumour.
\end{abstract}

Warthin's tumour, or adenolymphoma, occurs almost exclusively in the parotid gland ${ }^{1-3}$ where it accounts for $8 \%$ of tumours. ${ }^{2}$ Outside the parotid, it has been reported in juxtaparotid lymph nodes, the submandibular gland and, very rarely, in minor salivary glands of palate, cheek, lip and tongue. ${ }^{45}$ Lesions of identical histological appearance occur in the nasopharynx and could be mistaken for a rare example of extra-parotid Warthin's tumour. Friedmann, however, attributed the histological appearances of this lesion from the post-nasal space to a combination of chronic inflammation and hyperplasia of mucous glands, denying that it constituted a "true tumour".4

\section{Case report}

An 81 year old woman presented with leftsided otalgia and conductive hearing loss. A raised red plaque was present, obstructing the pharyngeal ostium of the left Eustachian tube. This was excised. The gross specimen consisted of a mucosal ellipse $0.5 \times 1.0 \mathrm{~cm}$ and $0.9 \mathrm{~cm}$ thick. Histological examination showed a well circumscribed, though not encapsulated, nodule of tissue $0.8 \mathrm{~cm}$ in maximum diameter with a microscopic appearance similar to that of a Warthin's tumour or adenolymphoma (fig 1). Cystically dilated ducts lined by partly infolded, double-layered oncocytic columnar epithelium were embedded in stroma rich in lymphocytes. Immunophenotyping of this lymphocytic stroma showed that these were $T$ cells (fig 2).

\section{Discussion}

The case described above and a similar recently reported case ${ }^{6}$ were both initially diagnosed as examples of extra-parotid Warthin's tumour of the nasopharynx. Both were subsequently diagnosed as oncocytic metaplasia in view of the reported rarity of Warthin's tumour in the nasopharynx. Indeed, the credibility of reports of Warthin's tumour outside the parotid is questioned by some authors. ${ }^{27}$

Oncocytic metaplasia, on the other hand, is a common occurence in both major and minor salivary glands, its incidence increasing with age. $^{2}$ When oncocytic metaplasia accompanied by dilatation of ducts occurs in close proximity to the ostium of an Eustachian tube it may cause obstruction, middle ear effusion, and 
Figure 1 Low power view of cystic spaces lined by oncocytic epithelium and a lymphocytic infiltrate. Note the papillary structures.

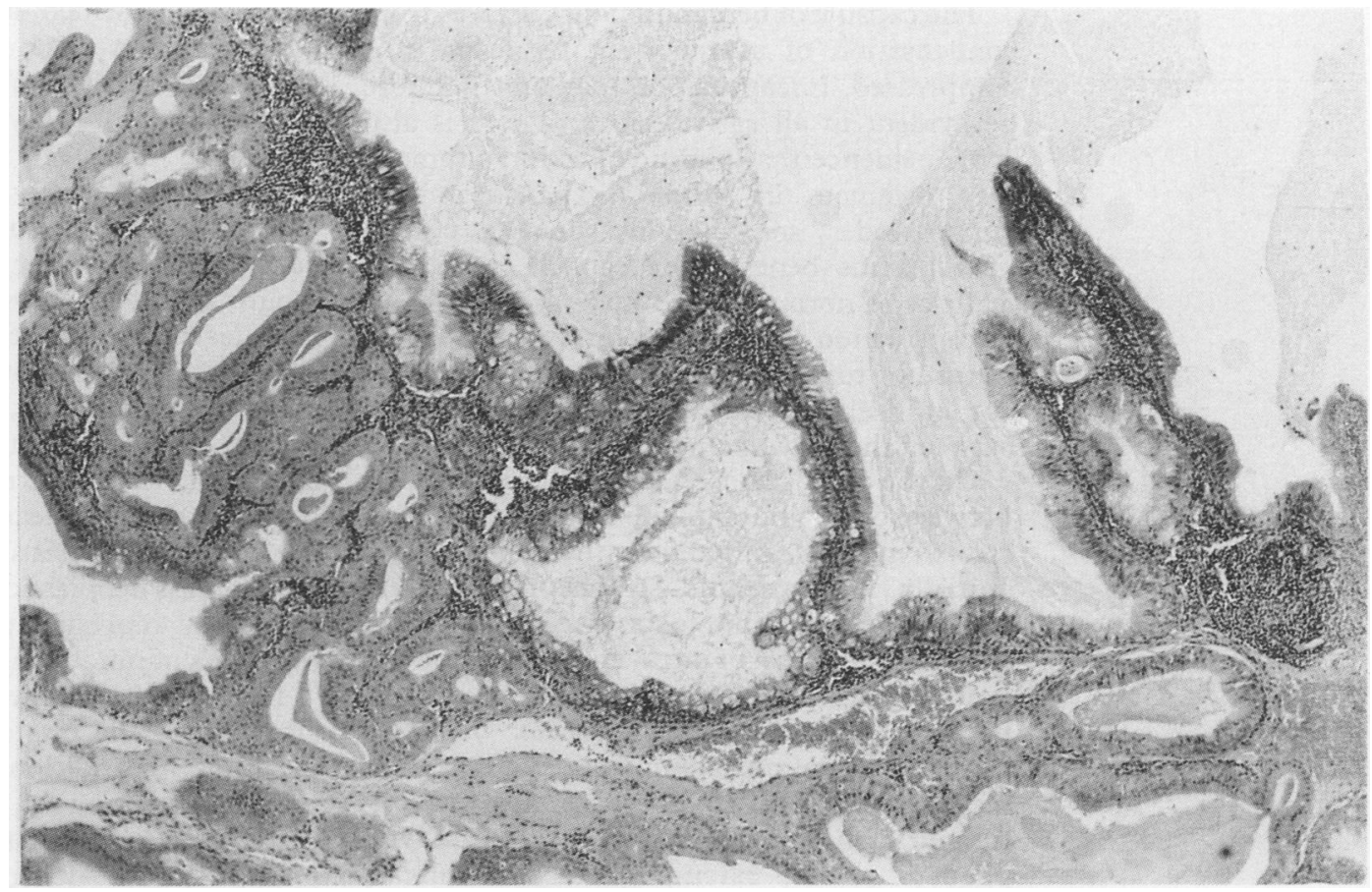

Figure 2 (A) Immunocytochemical staining for $C D 3, a T$ cell associated antigen: $(B)$ $L 26$, a $B$ cell associated antigen.

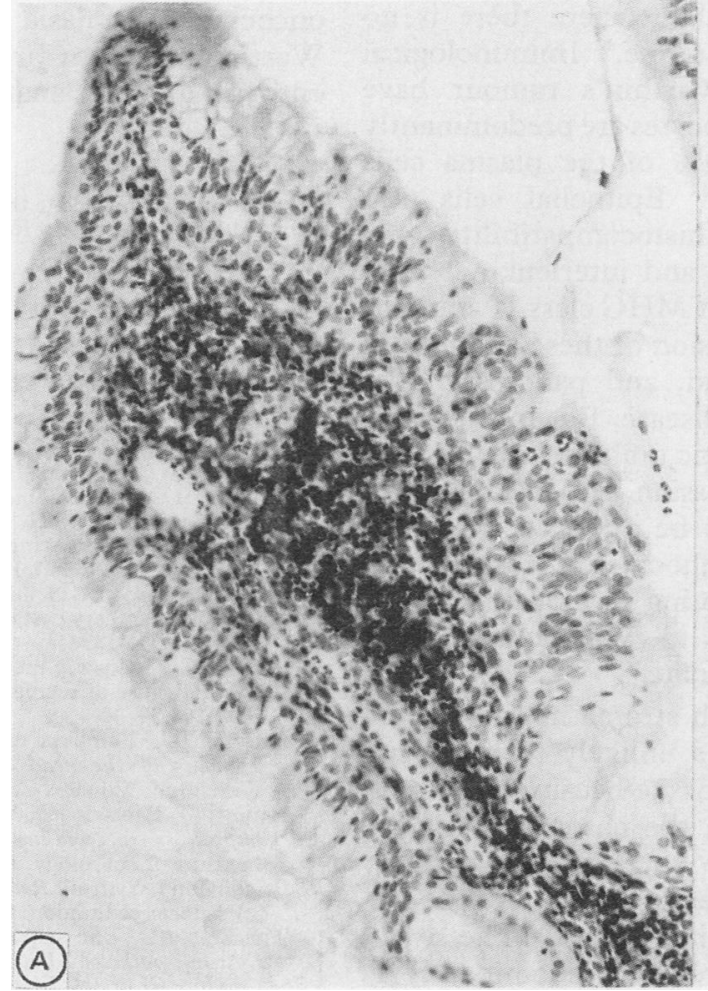

conductive hearing loss. Although peritubal oncocytic metaplasia receives brief mention in the Armed Forces Fascicle, ${ }^{8}$ there is no reference to this entity in two standard British textbooks devoted to oral ${ }^{2}$ and ear, nose, and throat pathology. ${ }^{3}$ Friedman' ${ }^{9}$ refers to oncocytic adenoma as a lesion occurring in the nasopharynx which may be confused with Warthin's tumour, stating that in the former the lymphocytes surround cystic spaces but do not occur in broad papillae protruding into the lumen. Such a papillary structure may be observed in our case (top left of fig 1). Perhaps the development of prominent intraluminal papillae is a feature of larger lesions.
Both Warthin's tumour of the parotid gland and oncocytic metaplasia of the nasopharynx show the classic ingredients of lymphocytic stroma intimately associated with a doublelayered oncocytic epithelium. Both entities occur in the elderly and have a benign course. Both lesions are well circumscribed, but Warthin's tumour of the parotid usually has a capsule, although this may often be incomplete. Is there any justification for distinguishing between these lesions on the basis - of encapsulation, or on the grounds that there is a difference in the nature of the association between the oncocytic epithelium and the lymphocytic stroma? 
The capsule of benign tumours derives from condensation of surrounding tissue as it is compressed. Encapsulation may not therefore be evident in all early lesions. There is also some evidence that parotid Warthin's tumour may originate in intra- or para-glandular lymph nodes, some lesions showing a peripheral sinus beneath the capsule and other features of normal lymph node architecture. ${ }^{10}$ Encapsulation may, therefore, represent a feature of tumour size and location, and may not in itself be a reason for distinguishing between these two pathological entities.

On the other hand, the nature of association between oncocytic epithelium and lymphocytic stroma might be different in these two lesions. Initially the lymphoid stroma in Warthin's tumour was thought to be derived from the normal population of intra- and para-glandular lymph nodes. The quantity of lymphoid tissue present, however, is much greater than that present in these small lymph nodes, ${ }^{11}$ and serial sections of parotid glands containing multiple tumours show tumour with typical lymphocytic stroma extending out into salivary gland lobules in clearly extra-nodal tissue. Classic Warthin's tumours have also been described in hard palate where there is no indigenous lymphoid tissue. ${ }^{12}$ Immunological studies of parotid Warthin's tumour have shown that the lymphocytes are predominantly $B$ cells $^{13}$ and that $80 \%$ of the plasma cells present secrete IgA. ${ }^{14}$ Epithelial cells also express class II major histocompatibility complex antigens (MHC) and interleukin-1 (IL1). ${ }^{15}$ This expression of MHC class II antigens is analogous to expression of these antigens in thyroid, salivary gland, and pancreatic islet cells in autoimmune disease. But in Sjögren's disease, the lymphocytic infiltrate is composed of T cells, and expression of MHC class II antigens is thought to be due to secretion of interferon $-\gamma$ by $\mathrm{T}$ lymphocytes. This presents a problem when attempting to explain the immunological findings in Warthin's tumour where $B$ cells predominate.

The lymphocyte rich stroma in our case of oncocytic metaplasia is unlikely to represent indigenous lymphoid tissue because the number of lymphocytes in the nasopharynx generally declines with age ${ }^{2}$ and lymphoid tissue is stated to occur only rarely at the level of the ostia of the Eustachian tubes. ${ }^{3}$ The lymphocytes in our case are also predominantly $T$ cells, a finding consistent with selective accumulation of lymphocytes in response to tissue-fixed antigen, but apparently at variance with the B cell constitution of parotid Warthin's tumour. If, however, our case of oncocytic metaplasia is truly a form of Warthin's tumour then, at $0.8 \mathrm{~cm}$ in diameter, it represents an early stage in the natural history of this lesion, parotid Warthin's tumours measuring on average $3.6 \mathrm{~cm}$ (range $1-8.5 \mathrm{~cm}){ }^{7}$ A possible explanation for the apparently paradoxical immunological findings in Warthin's tumour is that oncocytic metaplasia initially induces a $\mathbf{T}$ cell response which, as the lesion increases in size, recruits a much larger B cell population driven by a small number of $T$ cells. A study of the immunophenotype of small parotid tumours, and of larger nasopharyngeal tumours might clarify this.

The frequency with which oncocytic change occurs in the minor salivary glands of the mouth and nasopharynx may suggest that this is a degenerative phenomenon rather than a neoplastic process. Both Warthin's tumour and oncocytic metaplasia, however, consist of a lymphocytic reaction to proliferating oncocytic cells, and until the nature of the oncocytic process becomes clear we see no reason why oncocytic metaplasia should be regarded as any more or less neoplastic than Warthin's tumour. Both may represent points in a spectrum of disorders of mitochondrial function. ${ }^{16}$

In conclusion, we wish to draw pathologists' attention to the existence of oncocytic metaplasia as a condition likely to present as a tumourous lesion in the nasopharynx and a possible cause of Eustachian tube obstruction in the elderly. Although standard text books maintain that Warthin's tumour is rare outside the major salivary glands, is it not likely that oncocytic metaplasia of the nasopharynx and Warthin's tumour are the same pathological entity in different anatomical situations?

We gratefully acknowledge the assistance of Miss Juliet Hamblin and Mr Steve Toms for preparing the manuscript and photographs, respectively.

1 Eveson JW, Cawson RA. Warthin's tumor (cystadenolymphoma) of salivary glands. A clinico-pathological investigation of 278 cases. Oral Surg Oral Med Oral Pathol 1986;61:256-62.

2 Lucas RB. Pathology of tumours of the oral tissues. London: Churchill Livingstone, 1984

3 Michaels L. Ear, nose and throat histopathology. London: Springer-Verlag, 1987.
Sichels L. Ear, nose and

4 Friedmann I. Adenolymphoma of the salivary glands. $J$ Laryngol Otol 1953;67:165-9.

5 Baden E, Pierce M, Selman AJ, Roberts TW, Doyle JL. Intraoral papillary cystadenoma lymphomatosum. J Oral Surg 1976;34:533-41.

6 Watson C. Oncocytic metaplasia of the nasopharynx-an unusual cause of secretory otitis media. $J$ Laryngol Otol 1990;104:39-40.

7 Batsakis JG. Tumours of the major salivary glands. In: Tumours of the head and neck. 2nd edn. Baltimore: Williams \& Williams Co, 1979:1-75.

8 Hyams VJ, Batsakis JG, Michaels L. Tumours of the upper respiratory tract and ear. Washington, DC: Armed Forces respiratory tract and ear. Washingto

9 Friedmann I. Systemic Pathology. Volume 1. Throat, nose and ear pathology. London: Churchill Livingstone, 1986.

10 Thackray AC. The salivary glands. In: Morson BC, ed. Systemic pathology Vol 3. The alimentary tract. 3rd edn London: Churchill Livingstone, 1987:88-129.

11 Thackray AC, Lucas RB. Tumours of the major salivary glands. In: Firminger HI, ed: Atlas of tumour pathology. Second series. Fascicle 10. Washington, DC: Armed Force Institute of Pathology, 1974:40-53.

12 Fantasia JE, Miller AS. Papillary cystadenoma lymphomatosum arising in minor salivary glands. Oral Surg Oral Med Oral Pathol 1981;52:411-16.

13 Cossman J, Deegan MJ, Batsakis JG. Warthin tumor. Blymphocytes within the lymphoid infiltrate. Arch Pathol Lab Med 1977;101:354-6.

14 Hsu S-M, Hsu P-L, Ramakrishna NN. Warthin's tumor: an immunohistochemical study of its lymphoid stroma. Hum Pathol 1981;12:251-7.

15 Ogawa Y, Hong S-S, Toyosawa S, Chang C-K, Yagi T. Expression of major histochemical complex class II antigens and interleukin- 1 by epithelial cells of Warthin' tumor. Cancer 1990;15:2111-17.

16 Cotton DWK. Commentary: Oncocytomas. Histopathology 1990;16:507-9. 